\title{
Artigos
}

\section{Avaliação da interação em fóruns de discussão na especialização de preceptoria em Medicina de Família e Comunidade a distância}

\section{Assessment of interaction in discussion forums on distance learning specialization of preceptorship in Family and Community Medicine (abstract: p. 15) \\ Evaluación de la interacción en fórums de discusión en la especialización de preceptoría en Medicina de Familia y Comunidad a distancia (resumen: p. 15)}

\author{
Brenda Wander(a) \\ <brenda.br@gmail.com> \\ Marta Quintanilha Gomes ${ }^{(b)}$ \\ <martaqg@edu.ufcspa.br> \\ Maria Eugênia Bresolin Pinto(c) \\ <eugenia@ufcspa.edu.br> (iD)
}

\author{
(a) Médica de Família e \\ Comunidade. Avenida Protásio \\ Alves, 7157, 402/03, Bairro \\ Petrópolis. Porto Alegre, RS, \\ Brasil. 91310-003. \\ (b) Departamento de Educação e \\ Humanidades, Universidade \\ Federal de Ciências da Saúde \\ de Porto Alegre (UFCSPA). \\ Porto Alegre, RS, Brasil. \\ (c) Departamento de Saúde \\ Coletiva, UFCSPA. Porto \\ Alegre, RS, Brasil.
}

Esta pesquisa busca compreender que critérios são importantes para a percepção do aluno da qualidade da interação e interatividade na Educação a Distância (EAD). 0 estudo transversal objetivou analisar como ocorreu a interação em fóruns de um curso tutorado, a distância, de especialização de preceptoria em Medicina de Família e Comunidade (MFC), com análises complementares de abordagem quantitativa e qualitativa. Após estimar a qualidade da interação e interatividade do curso na percepção dos alunos, foram selecionados dois grupos e então analisados 16 fóruns utilizando princípios da análise da conversação. 0 número de mensagens postadas, de intervenções do tutor e de cadeias enunciativas foi associado à qualidade. Os resultados mostram que a autonomia na atuação do tutor, como propor mudanças de tópico, incide na participação e na construção de cadeias enunciativas, que contribuem para a percepção da qualidade da interação e interatividade.

Palavras-chave: Educação a distância. Relações interpessoais. Preceptoria. Medicina de família e comunidade.

Wander B, Gomes MQ, Pinto MEB. Avaliação da interação em fóruns de discussão na especialização de preceptoria em Medicina de Família e Comunidade a distância. Interface (Botucatu). 2020; 24 (Supl.1): e190513 https://doi.org/10.1590/Interface.190513 


\section{Introdução}

A EAD é caracterizada pelo processo de ensino-aprendizagem ocorrer em tempo e espaço diversos e de forma mediada pela tecnologia. Com o avanço das tecnologias da informação, a EAD ampliou o acesso à informação e à construção do conhecimento por meio da formação em larga escala. A educação superior a distância no Brasil dispunha, em 2004, de cerca de sessenta mil alunos matriculados e atingiu, em 2016, a marca de 1,5 milhão de matrículas, oferecendo importante colaboração para o desenvolvimento do país ${ }^{1}$. Na área da Saúde, há o investimento em formação permanente de profissionais na modalidade EAD. Para isso, vários desenhos de cursos que vêm sendo elaborados buscam dar capilaridade aos processos formativos de forma qualificada. Em agosto de 2019, a rede da Universidade Aberta do Sistema Único de Saúde (UNA-SUS), iniciativa de formação a distância gratuita voltada à formação de profissionais de saúde, contabilizava 2.412 .406 de matrículas e contemplava todas as unidades da federação, conforme a plataforma Arouca $^{(\mathrm{d})}$. É nessa esteira - pensar no processo de educação na saúde no contexto da EAD - que tal investigação se coloca.

Inicialmente alvo de preconceito da comunidade acadêmica, tal modalidade vem conquistando respeito com a EAD tutorada, que possibilitou a interação entre tutor e aluno e a construção do conhecimento de forma coletiva. Porém, há diferenças entre a interação em aulas presenciais e a interação em um ambiente virtual de aprendizagem. O contato direto que a aula presencial proporciona, que permite comunicação verbal e não verbal, é substituído pela interação mediada pelo computador (na maioria das vezes, com comunicações assíncronas e escritas), o que pode aumentar a sensação de distanciamento do tutor ou professor por parte do aluno. Com a crescente utilização desse modelo educacional no Brasil, é importante haver estudos sobre os fatores que interferem na qualidade dos processos em EAD e que colaborem com a compreensão dos processos interativos. Tais estudos ajudam a explicar a maneira como ocorre a aprendizagem com o apoio das tecnologias.

$\mathrm{Na}$ EAD, deve-se ter uma preocupação com a evolução tecnológica e com a evolução pedagógica, uma vez que a experiência nessa área já mostrou que não é somente a tecnologia que garante o sucesso de tal modalidade, mas também a pedagogia preocupada com o papel do professor, que precisa "saber como fazer" a EAD2. Uma das vantagens que se tem atribuído à comunicação nesta modalidade é o aumento da interação entre professores e alunos, já que permite estender o tempo e o espaço de trabalho que normalmente se utiliza nas aulas presenciais, gerando potencialmente maiores oportunidades para a aprendizagem ${ }^{3}$. Os cursos EAD, por meio dos ambientes virtuais de aprendizagem, possibilitam a comunicação com ferramentas síncronas, tais como chat, além de comunicações assíncronas, tais como fóruns ${ }^{4}$. O fórum de discussão é uma ferramenta interativa assíncrona frequentemente utilizada nos modelos de EAD de orientação construtivista ${ }^{5}$, sendo que a utilidade dessa ferramenta como potencializadora da aprendizagem depende diretamente da interação aluno-tutor e aluno-aluno. Fóruns podem ser considerados cenários propícios para a construção de conhecimento de forma compartilhada, desde que, efetivamente, neles ocorram processos interativos ${ }^{6}$. Dessa forma, é importante a análise da qualidade de interação desses cenários, a fim de que haja condiçôes de ofertar ambientes de aprendizagem mais adequados. (d) Informação da Plataforma Arouca, disponível on-line em unasus.gov.br, acessada em 5 de agosto de 2019. 
Além do papel do tutor, cuja importância na função de mediar o processo de aprendizagem do aluno é fundamental, o sucesso da EAD, entendida como um instrumento ef icaz de aprendizagem, também está na postura do aluno, ou seja, no seu envolvimento no processo educacional. Nesse sentido, cabe ao aluno sair da posição passiva de espectador e assumir o papel principal, interagindo, colaborando e cooperando. A modalidade educacional a distância exige do aluno uma postura ativa: implica compromisso, iniciativa, autonomia e disciplina, ao mesmo tempo que exige do tutor, além do domínio do conteúdo estudado, o estabelecimento de diálogo constante com alunos e o estímulo à participação destes?

O curso que é cenário do presente estudo tem em seu projeto pedagógico a premissa de esculpir um processo de ensino-aprendizagem que considera o conhecimento como construção permanente. Além disso, entende ser importante estabelecer um processo relacional em que o professor e o tutor desenvolvam estratégias que garantam a interação dos alunos de forma ativa e autônoma. Esses princípios levam a um modelo pedagógico sustentado pela teoria de aprendizagem interacionista. Em tal abordagem, a ação do sujeito é colocada no cerne do processo de aprendizagem, e professor e aluno trazem sua bagagem de conhecimento ${ }^{8}$.

O conceito de interação é entendido neste estudo a partir de uma perspectiva epistemológica interacionista que considera interação como relaçóes sociais que se estabelecem a partir das comunicaçóes dialógicas que ocorrem entre os membros de um grupo com a finalidade de promover a aprendizagem". O termo "interatividade" muitas vezes é utilizado como sinônimo de interação, porém, a interatividade diferenciase da interação por estar relacionada com os atributos da tecnologia utilizada na EAD, aparentemente emergindo de descriçốes da capacidade tecnológica de estabelecer conexôes de ponto a ponto ${ }^{10}$. Ou seja, a interação está associada às pessoas e diretamente relacionada à atuação do tutor e do aluno, enquanto a interatividade está associada à tecnologia e aos canais de comunicação. Nesse sentido, são importantes os esforços em não reduzir a EAD à tecnologia em detrimento da interação necessária entre os participantes.

Este artigo apresenta parte de uma pesquisa realizada em um curso de especialização de preceptoria em MFC oferecido a médicos residentes dessa especialidade médica, no modelo pedagógico relacional e tutorado. Esta pesquisa teve como objetivo analisar como ocorreu a interação em fóruns de discussão na primeira oferta do curso.

\section{Metodologia}

Trata-se de um estudo transversal, com abordagem metodológica quantitativa e qualitativa, complementares para alcançar o objetivo proposto e que teve como cenário um curso de especialização na modalidade pós-graduação lato sensu, a distância, destinado à formação de especialistas que possam desenvolver as atividades de preceptoria qualificada de residência e graduação em Medicina na Atenção Primária à Saúde. O curso foi dividido em oito unidades de estudo, com um módulo de preceptoria em cada uma, um módulo de casos clínicos complexos e uma atividade integradora, que tem como propósito articular conteúdos da preceptoria aos de clínica da MFC. Tanto o módulo de preceptoria (o primeiro módulo de cada unidade) quanto os casos complexos dispóem de fóruns de discussão que permitem interação aluno-aluno e aluno-tutor. 
Durante a última unidade de ensino da primeira oferta do curso, os 879 alunosresidentes ativos dos 28 grupos do curso foram convidados a responder um questionário que incluía o instrumento adaptado de Roblyer e Wiencke ${ }^{11}$. Esse instrumento foi desenvolvido para uso em cursos a distância em que um instrutor está disponível para um grupo específico de alunos e classifica a qualidade da interação e interatividade como alta, moderada e baixa, por meio de pontuação de um a cinco em cada um de cinco elementos, gerando um escore total que varia de cinco a 25 . Segundo os autores, tais elementos, essenciais para determinar a qualidade da interação nos cursos a distância, são:

- Design de interação social - diz respeito à possibilidade de interaçóes com troca de informaçốes pessoais não relacionadas especificamente ao conteúdo do curso.

- Design instrucional para a interação - inclui as atividades relacionadas ao conteúdo que permitem interação entre os participantes.

- Interatividade das tecnologias - diz respeito às características das tecnologias utilizadas no curso e aos tipos de interação que elas permitem.

- Evidência de engajamento do aluno.

- Evidência de engajamento do tutor.

Após a aplicação do questionário, foi feita a classificação da interação e interatividade por grupo. Depois, foram selecionados dois grupos do curso para análise de fóruns do módulo específico de preceptoria de cada uma das oito unidades de ensino. A escolha pelos grupos para a análise de fóruns se deu por aquele cujo processo interativo foi mais bem avaliado e aquele em que este foi pior avaliado, na percepção dos alunos. Para essa escolha, devido à discrepância entre o número de respondentes nos grupos, foram incluídos os que tiveram pelo menos $24 \%$ de alunos respondendo ao questionário.

A abordagem qualitativa, que utiliza princípios do método de análise da conversação, analisou as características da interação nessa ferramenta, com foco na atuação do tutor, ao buscar relacioná-las à qualidade da interação percebida por meio dos instrumentos aplicados inicialmente. Tal método, apesar de descrito e tradicionalmente utilizado para análise de conversação presencial ${ }^{12}$, mostrou-se útil na análise de interação em ambiente virtual, no qual ocorre um tipo particular de conversação que se efetua por meio do texto escrito $^{5}$ e que mantém a possibilidade de construção de cadeias enunciativas, foco de análise nessa metodologia de pesquisa.

Para fins deste estudo, entende-se que uma sequência ou cadeia enunciativa é uma série de turnos sucessivos que se ligam por alguma razão. Seguindo como modelo a análise realizada por Bicalho e Oliveira ${ }^{5}$, as mensagens de cada fórum foram organizadas em cadeias, com base nos seguintes critérios: envolvimento de, no mínimo, três interlocutores diferentes, incluindo o tutor (desconsidera-se a postagem de abertura do fórum), e coerência entre o assunto enfocado nas mensagens e o tópico acadêmico do fórum de discussão. Mudanças de tópico ocorrem quando o tópico chegou ao fim. Outra marcação é a quebra de tópico, que ocorre quando este foi interrompido, mas pode retornar ${ }^{12}$. Nesta pesquisa, ambas as situaçốes serão chamadas de "troca de tópico".

O projeto desta pesquisa foi aprovado pelo Comitê de Ética em Pesquisa da Universidade Federal de Ciências da Saúde de Porto Alegre (UFCSPA), sob o parecer n. 2.465.993. 


\section{Resultados}

Houve 204 respostas ao questionário (23\% dos alunos), sendo que 15 grupos tiveram $24 \%$ ou mais de alunos respondentes. A pontuação geral atribuída ao curso foi de 14,8 , resultado que estima a interação e interatividade como moderada. Entre os 28 grupos, quatro obtiveram pontuação de alta interação e interatividade e nenhum obteve pontuação de baixa interação e interatividade. O grupo mais bem avaliado, aqui denominado "X", recebeu uma pontuação de 19,1, o que o classifica como um grupo de alta interação e interatividade. Por outro lado, o grupo pior avaliado, aqui denominado “Z”, recebeu uma pontuação de 11,8 , o que o classifica como de moderada interação e interatividade. Ao total, foram analisados 16 fóruns, oito de cada grupo.

O número de mensagens postadas nos fóruns de discussão, de intervenções do tutor e de cadeias enunciativas diferiu entre os grupos " $X$ ” e "Z", o que pode ser visto na tabela 1.

Tabela 1. Total de mensagens e cadeias enunciativas nos fóruns de discussão, desconsiderando a postagem do tutor de abertura do fórum

\begin{tabular}{lccc}
\hline Grupo & X & Z & Total \\
\hline $\begin{array}{l}\text { Todas as mensagens postadas nos oito fóruns de } \\
\text { discussão } \\
\text { Intervenções do tutor }\end{array}$ & 783 & 472 & 1255 \\
\hline Total de cadeias enunciativas & 256 & 75 & 331 \\
\hline Total de mensagens nas cadeias & 52 & 23 & 75 \\
\hline
\end{tabular}

Fonte: Os autores.

Pode-se perceber que, em ambos os grupos, mais da metade das mensagens postadas nos fóruns foram realizadas no intuito de cumprir tarefa, sem relação necessária entre si, na conversação com o tutor ou colegas. Na separação desses dados por fórum, também é possível perceber que nem a distribuição das mensagens, nem a participação dos tutores são homogêneas ao longo do curso. As trocas de tópico ao longo da conversa nos fóruns ocorreram predominantemente no grupo $\mathrm{X}$, tendo ocorrido apenas uma vez no grupo $\mathrm{Z}$. Tais observaçôes podem ser vistas nas tabelas 2 e 3 : 
(2)

Tabela 2. Análise dos fóruns do grupo X

\begin{tabular}{cccccc}
\hline Fórum & $\begin{array}{c}\text { Número de } \\
\text { postagens }\end{array}$ & $\begin{array}{c}\text { Intervenções } \\
\text { do tutor }\end{array}$ & Cadeias enunciativas & $\begin{array}{c}\text { Total de mensagens } \\
\text { nas cadeias }\end{array}$ & $\begin{array}{c}\text { Trocas de } \\
\text { tópico }\end{array}$ \\
\hline 1 & 230 & 71 & 21 & 189 & 13 \\
2 & 145 & 62 & 11 & 71 & 7 \\
3 & 68 & 25 & 3 & 19 & 1 \\
4 & 88 & 39 & 2 & 12 & 1 \\
5 & 120 & 47 & 11 & 62 & 0 \\
6 & 28 & 1 & 0 & 0 & 0 \\
7 & 44 & 1 & 1 & 5 & 1 \\
\hline Total & 60 & 10 & 3 & 14 & 25 \\
\hline
\end{tabular}

Fonte: Os autores.

Tabela 3. Análise dos fóruns do grupo Z

\begin{tabular}{cccccc}
\hline Fórum & $\begin{array}{c}\text { Número de } \\
\text { postagens }\end{array}$ & $\begin{array}{c}\text { Intervenções } \\
\text { do tutor }\end{array}$ & $\begin{array}{c}\text { Cadeias } \\
\text { enunciativas }\end{array}$ & $\begin{array}{c}\text { Total de mensagens } \\
\text { nas cadeias }\end{array}$ & Trocas de tópico \\
\hline 1 & 61 & 7 & 3 & 32 & 0 \\
\hline 2 & 108 & 40 & 9 & 54 & 0 \\
\hline 3 & 43 & 0 & 0 & 0 & 0 \\
\hline 5 & 46 & 0 & 0 & 0 & 0 \\
\hline 6 & 82 & 22 & 8 & 44 & 1 \\
\hline 7 & 42 & 0 & 0 & 0 & 0 \\
\hline Total & 472 & 4 & 2 & 10 & 1 \\
\hline
\end{tabular}

Fonte: Os autores 
No grupo $\mathrm{X}$, nos fóruns 3 , $4 \mathrm{e} 8$, percebe-se um grande esforço do tutor tentando motivar maior participação nos fóruns ao responder às postagens dos alunos e fazer questionamentos, ainda que sem posterior retorno deles. Por exemplo, no fórum 4 , são 14 postagens do tutor com perguntas que não foram respondidas pelos alunos. No grupo Z, há um número inferior de questionamentos aos alunos em relação ao grupo $\mathrm{X}$. Nesse grupo, apesar da falta de resposta do aluno ao tutor em vários momentos, no fórum 4 fica evidente que, apesar da ausência do tutor, houve evidência de engajamento dos alunos, que fizeram 46 postagens ao total, com interaçôes exclusivamente entre os alunos. Também no grupo Z, no fórum 1 , apesar de poucas cadeias identificadas com a participação do tutor, houve pelo menos três interações, cada uma delas entre pelo menos três alunos, porém, sem participação do tutor. Por isso, tais dados não foram contabilizados como cadeia enunciativa para fins deste estudo.

As trocas de tópico realizadas no grupo $\mathrm{X}$, em sua maioria, foram motivadas pelo tutor, com assuntos pertinentes à discussão, sempre retornando ao tópico principal e tentando achar correlaçóes entre os assuntos propostos e a pergunta norteadora do fórum. De forma contrária, no grupo $\mathrm{Z}$ houve apenas um fórum em que ocorreu uma mudança de tópico, fato motivado por um aluno.

Um exemplo dessa postura do tutor pode ser visto no fórum 1 do grupo $\mathrm{X}$, que teve o maior número de trocas de tópico e de cadeias enunciativas entre todos os analisados. Nesse fórum, o tutor participa ativamente, ao criar postagens elaboradas, com conteúdo técnico, mas também afetivo, como o exemplo:

[Nome do aluno] e demais, isso de ficar repetindo que concordou não é muito saudável para todos, pois vai encher a gente de postagem inútil aqui [...]. Creio que seja a vontade de todos nós de termos um debate enriquecedor [...]. Mas, aproveitando a deixa, concordo quando falas que nosso trabalho é nossa vitrine sempre [...]. (Tutor)

O tutor frequentemente inicia sua participação comentando a postagem do aluno e depois coloca a sua contribuição. Ao longo do fórum, há 13 trocas de tópico. Inicialmente, o tutor questiona sobre um sistema de saúde baseado na Atenção Primária em Saúde (APS) e em qual rumo está o país. Após o assunto se desenvolver e ao responder a uma aluna, o tutor estabelece uma relação entre longitudinalidade na APS, melhoria do atendimento e maior confiança por parte do paciente. A partir daí, relaciona a longitudinalidade a uma questão que a aluna levantou sobre renovação de receitas na Unidade de Saúde, ao mesmo tempo que questiona como tal processo pode ser melhorado. Isso gera nova participação de colegas que já haviam respondido à pergunta norteadora do fórum, na tentativa de colaborar com a solução de um problema dentro do tópico principal - a APS como base do sistema de saúde. Após outras postagens, o tutor acaba refletindo sobre quando a atuação do médico de família na APS é custo-efetiva. Dessa forma, vários outros tópicos vão sendo discutidos no fórum, até que, por fim, o tutor propóe questóes sobre características de um médico de família ideal, como estimular tais características nos alunos e como fazer isso em uma especialização virtual. Ou seja, culmina em uma relação com a especialização em preceptoria que não parecia prevista no início do fórum, o que não ocorre no outro grupo. 
É possível verificar um critério de análise que aproxima ambos os grupos que diz respeito à diminuição de interação no desenvolvimento do curso, com duração de 22 meses. No grupo X, percebe-se menor participação e interação com o passar do curso, sendo que o fórum 6 foi aberto com atraso e, apesar do baixo número de postagens (28) e de não possuir cadeias enunciativas com a participação do tutor, apresenta quatro diálogos exclusivamente entre alunos. Tal interação mostrou uma postura de autonomia do aluno na discussão do tópico.

O fato de o tutor se dirigir nominalmente aos alunos durante a discussão pode ser percebido predominantemente nos fóruns do grupo X. No grupo Z, o tutor em geral não se dirige nominalmente aos alunos, o que torna o fórum confuso em vários momentos, sendo por vezes difícil perceber os turnos de fala de cada um nas cadeias enunciativas.

$\mathrm{Na}$ análise dos tópicos discutidos nos fóruns, percebe-se que, no fórum 5 do grupo $Z$ (sobre prevenção quaternária), o tutor participou mais que em outros fóruns, porém, fez poucos questionamentos. Depreende-se, ainda, a segunda maior participação geral ( 82 postagens) e o segundo maior número de cadeias enunciativas do grupo. No fim desse fórum, o grupo consegue correlacionar vários conceitos da especialidade Medicina de Família e Comunidade com a prevenção quaternária. O interesse pelo assunto também parece estar evidenciado no mesmo fórum do grupo $\mathrm{X}$, que teve 120 postagens.

Ainda sobre os tópicos discutidos, na abertura do fórum 2 do grupo $Z$, o tutor muda parcialmente o tópico proposto pelo curso ao focar a pergunta no método de registro de consulta. Ao longo do fórum, sua participação demonstra seu interesse no assunto. Dessa forma, esse se tornou o fórum com o maior número de postagens desse grupo (108), a maior participação do tutor ( 40 intervenções) e o maior número de cadeias (nove). Da mesma forma, na abertura do primeiro fórum do grupo X, já descrito anteriormente, houve mudança na pergunta norteadora, fomentando uma discussão que, conforme foi avançando, relacionou o assunto inicial com o módulo da unidade de ensino vigente. Isso ocorreu devido à forma como o tutor guiou o fórum. No fim, esse fórum foi, entre todos, o que teve maior participação, tanto dos alunos quanto do tutor.

\section{Discussão}

A perceptível diferença entre os grupos na quantidade de mensagens postadas e na participação do tutor, além do número de cadeias enunciativas com a participação do tutor, mostra que a percepção da qualidade da interação e interatividade do curso como um todo passa obrigatoriamente pela qualidade da interação aluno-tutor nos fóruns. Segundo $S_{w a n}{ }^{13}$, os cursos mais bem-sucedidos são os que a interação aluno-tutor é tanto frequente quanto produtiva. Além disso, o autor ressalta a importância da interação social e entre os próprios estudantes para o sucesso de tais cursos, uma vez que parece ser esse um dos fatores mais importantes nos cursos on-line. Já segundo Roblyer e Wiencke ${ }^{14}$, a percepção dos alunos sobre a interação não parece se correlacionar com número de mensagens ou tempo gasto na interação. Diversamente, a percepção parece ser influenciada pela qualidade e utilidade de tal interação ${ }^{14}$. 
A atitude do tutor de se dirigir nominalmente aos alunos durante a discussão, mais frequente no grupo com melhor avaliação, é um fator motivador, dado que torna a conversa mais pessoal e demonstra interesse na fala do aluno. Um ambiente virtual de aprendizagem em que há trocas amigáveis e abertas entre estudantes e tutor é provavelmente mais produtivo do ponto de vista educacional do que um ambiente em que as trocas são formais e limitadas. Também nesse sentido, no estudo de Abovsky et al. ${ }^{15}$, foi observado que a capacidade empática dos tutores influi positivamente na percepção dos alunos nos fóruns e que sua ausência influi de modo negativo ${ }^{15}$. A menor participação tanto do tutor quanto dos alunos com o passar do tempo, em ambos os grupos, possivelmente se deve à extensão do curso, que durou ao todo 22 meses. Apesar disso, a percepção da interação por parte dos alunos no grupo X permaneceu boa, provavelmente pela postura de parceria com o aluno que o tutor assumiu ao longo de todo o curso, mesmo quando sua participação diminuiu.

Ainda sobre a forma como o tutor se dirige aos alunos e com eles se comunica, alguns autores levantam a questão da importância da afetividade no ambiente virtual e como ela deve ser incorporada como atitude do tutor. Segundo Vieira e Abreu ${ }^{4}$, o tutor precisa desenvolver a criação de um ambiente amigável, a fim de facilitar o processo de ensino e aprendizagem. Para isso, ele deve agir com o objetivo de construir um relacionamento afetivo, estimular a participação do aluno, ter uma comunicação cordial, destacar o crescimento individual e grupal, entre outros. Para Daudt e Behar ${ }^{16}$, para além do conhecimento do conteúdo ou da tecnologia, a capacidade de estabelecer uma comunicação afetiva com os estudantes é um elemento que se destaca sobre o perfil desejado para professores e tutores.

Os questionamentos não respondidos ao longo das discussões são uma evidência de falta de engajamento do aluno em contraste com o engajamento do tutor ao tentar motivar a participação e troca de experiências. Porém, quando é observado o grupo interagindo na ausência do tutor, essa participação provavelmente potencializa o aprendizado e mostra interesse do grupo em participar e interagir independentemente de um mediador. A postura ativa e autônoma esperada do aluno em EAD tanto é possível quanto pode ser encorajada. Nesse sentido, Tello ${ }^{17}$ sugere que, quando a frequência da interação aluno-tutor aumenta em um curso, a frequência da interação aluno-aluno também aumenta. Os tutores dividem com os alunos a responsabilidade de promover a aprendizagem interativa, sendo que os tutores podem criar um ambiente que conduz a uma alta interação e autonomia do aluno ${ }^{11}$.

A iniciativa de propor novos rumos para a discussão, ao mudar o tópico ao longo da conversa, desde que coerente com o assunto principal do fórum, motiva a participação, o que pode ser visto pela quantidade de cadeias nos fóruns em que houve mais mudanças ao longo da discussão e pela percepção de melhor qualidade da interação e interatividade no grupo em que houve tais trocas. A abertura do fórum com um tópico diferente do sugerido no curso e alguns assuntos específicos também parecem gerar por si só maior participação e discussão. Possivelmente, isso se deve ao interesse pessoal tanto do tutor quanto dos alunos pelo assunto do fórum, como se viu nos fóruns sobre prevenção quaternária ou naqueles em que o tutor escolheu um tópico de abertura diferente do original do curso. 
Em se tratando da educação de adultos, a motivação para adquirir novos conhecimentos está fortemente vinculada ao suprimento dos seus interesses e necessidades ${ }^{4}$, ou seja, a aquisição do conhecimento tem uma utilidade prática, assim como pode ser influenciada pela necessidade e pelo interesse pessoal. No curso que foi base para este estudo, quem exerce a tutoria é um médico, especialista na área e com experiência em preceptoria. Nesse sentido, é importante que o tutor domine os assuntos de maior interesse da especialidade e tenha boa percepção dos interesses do seu próprio grupo.

O tutor, para cumprir seu papel de mediação pedagógica, deve manter um diálogo constante com os alunos e estimular a interação social. No entanto, para além disso, os achados deste estudo sugerem que, ao estimular a autonomia do tutor e permitir que ele defina os tópicos que serão discutidos juntamente com o grupo sob sua responsabilidade, o tutor estará agindo em conjunto com os professores conteudistas, o que amplia sua função de docente e colabora com a qualidade do curso em EAD. Autores defendem que a nomenclatura correta seja “professor-tutor”, ${ }^{4}, 18$, uma vez que o tutor a distância é também considerado um docente e está cada vez mais envolvido com o processo de ensino: é um facilitador da aprendizagem e avaliador de competências, e não um mero distribuidor de conteúdo ${ }^{19}$.

De forma geral, percebe-se também em ambos os grupos o potencial do fórum como forma de problematizar o dia a dia dos residentes. O tutor tem claramente oportunidades de ajudar na formação dos residentes da MFC e acrescentar discussões que nem todos os programas de residência conseguem levantar.

Como limitação deste estudo, vale ressaltar que o instrumento utilizado para escolha dos grupos para análise, adaptado do original em inglês, ainda não teve sua versão em português validada. A taxa de resposta também pode ser considerada uma possível limitação. No entanto, é importante ressaltar que este foi um curso de abrangência nacional, com grande quantidade de alunos, e houve respondentes em todos os grupos do curso. Como os dois grupos que foram comparados tinham avaliaçóes bastante diferentes entre si (com escores de qualidade de interação e interatividade alta e moderada), os resultados se mantêm úteis para a prática em EAD.

\section{Conclusão}

A percepção da interação e interatividade do curso foi influenciada por características da interação aluno-tutor percebidas nos fóruns estudados, como a forma em que a discussão é guiada pelo tutor, a forma como este se dirige aos alunos e sua participação nos fóruns, cujas diferenças foram manifestas entre os grupos. Para motivar a participação dos alunos e promover a aprendizagem, o tutor deve exercer o papel de docente, com autonomia para guiar a discussão, ao criar correlaçóes entre os assuntos da especialidade ou mesmo mudando o rumo da discussão, desde que mantenha assuntos pertinentes à questão principal do fórum.

Devido à importância da interação para o processo de aprendizagem e seu potencial motivador e problematizador, o modelo tutorado deve ser incentivado nos cursos em 
EAD na área da MFC. Da mesma forma, maior atenção deve ser dada à formação do tutor, tanto na formação acadêmica de sua especialidade quanto em sua formação pedagógica como docente em EAD.

Mais estudos são necessários para melhor compreensão da interação nos fóruns e do processo interativo como um todo nos cursos na modalidade a distância ao se considerar também a importância de apresentar dados complementares quantitativos e qualitativos, o que aumenta a relevância dos achados. Outrossim, é importante que se pesquise sobre fatores que influenciam no processo interativo, especialmente em sua relação com outros aspectos não estudados na pesquisa que originou este artigo, como seu impacto na evasão.

\section{Contribuições das autoras}

Todas as autoras participaram ativamente de todas as etapas de elaboração do manuscrito.

\section{Direitos autorais}

Este artigo está licenciado sob a Licença Internacional Creative Commons 4.0, tipo BY (https://creativecommons.org/licenses/by/4.0/deed.pt_BR).

\section{(cc) BY}




\section{Referências}

1. Bielschowsky CE. Qualidade na educação superior a distância no Brasil: onde estamos, para onde vamos? EaD Foco. 2018; 8(1):e709.

2. Tarouco LMR, Moro ELS, Estabel LB. O professor e os alunos como protagonistas na educação aberta e a distância mediada por computador. Educ Rev. 2003; (21):29-44.

3. García Cabrero B, Márquez L, Bustos A, Miranda GA, Espindola S. Análisis de los patrones de interacción y construcción del conocimiento en ambientes de aprendizaje en línea: una estrategia metodológica. REDIE Rev Eletronica Investig Educ. 2008; 10(1):1-19.

4. Vieira CMS, Abreu RMA. Educação a distância: uma reflexão sobre a relação professor-tutor e estudante no processo de ensino e aprendizagem. Intersaberes. 2016; 11(23):284-303.

5. Bicalho RNM, Oliveira MCSL. The dialogic process of knowledge construction in discussion forums. Interface (Botucatu). 2012; 16(41):469-83.

6. Faria MGA, Acioli S, Taborda M, Gallasch CH. Aspectos contemporâneos da construção compartilhada do conhecimento: uma perspectiva virtual. REME Rev Min Enferm. 2018; 22:e-1089.

7. Konrath MLP, Tarouco LM, Behar PA. Competências: desafios para alunos, tutores e professores em EaD. RENOTE Rev Novas Tecnol Educ. 2009; 7(1):1-10.

8. Neves R, Damiani MF. Vygotsky e as teorias da aprendizagem. UNIrevista. 2006; $1(2): 1-10$.

9. Batista EM, Gobara ST. Interação na pedagogia a distância de uma instituição pública brasileira. Interacçốes. 2015; 37:124-149.

10. Wagner ED. Interactivity: from agents to outcomes. New Dir Teach Learn. 1997; (71):19-26.

11. Roblyer MD, Wiencke WR. Design and use of a rubric to assess and encourage interactive qualities in distance courses. Am J Distance Educ. 2003; 17(2):77-98.

12. Marcuschi LA. Análise da conversação. São Paulo: Ática; 2003.

13. Swan K. Virtual interaction: design factors affecting student satisfaction and perceived learning in asynchronous online courses. Am J Distance Educ. 2001; 22(2):306-31.

14. Roblyer MD, Wiencke WR. Exploring the interaction equation: validating a rubric to assess and encourage interaction in distance courses. JALN. 2004; 8(4):25-37.

15. Abovski A, Alfaro JA, Ramírez MS. Relaciones interpersonales virtuales en los procesos de formación de investigadores en ambientes a distancia. Sinectica. 2012; 39:1-14.

16. Daudt SID, Behar PA. A gestão de cursos de graduação a distância e o fenômeno da evasão. Educação. 2013; 36(3):412-21.

17. Tello SF. Examining instructional interaction and student persistence in online education. In: Mehdi Khosrow-Pour DBA. Managing worldwide operations \& communications with information technology. Hershey: IGI Global; 2007. p. 544-7.

18. Mattar J. Tutoria e interação em educação à distância. São Paulo: Cengage Learning; 2012.

19. Oliveira DAMR, Melo VL, Duarte ESA, Sá SPC, Andrade M, Cavalcanti ACD. Atuação do tutor no ensino superior a distância: revisão integrativa. J Nurs UFPE. 2014; 8(4):1029-37. 
This research aims at understanding which criteria are important for the students' perception of quality of interaction and interactivity in distance education. The transversal study aimed at analyzing the interaction in discussion forums on distance learning specialization of preceptorship in Family and Community Medicine with complementary analyses of quantitative and qualitative approach. After estimating the quality of the course's interaction and interactivity in students' perception, two groups were selected, and 16 forums were analyzed based on the principles of conversation analysis. The number of posted messages, tutor interventions, and enunciation chains were associated with quality. The results show that tutor's autonomy, such as suggesting change of topic, influences participation and construction of enunciation chains that contribute to the perception of quality of interaction and interactivity.

Keywords: Distance education. Interpersonal relations. Preceptorship. Family and community medicine.

Este estudio buscó entender qué criterios son importantes para la percepción del alumno de la calidad de la interacción e interactividad en la Educación a Distancia. El estudio transversal tuvo el objetivo de analizar cómo sucedió la interacción en forums de discusión de un curso tutorado, a distancia, de especialización de preceptoría en Medicina de Familia y Comunidad, con análisis complementarios de abordaje cuantitativo y cualitativo. Después de estimar la calidad de la interacción e interactividad del curso, bajo la percepción de los alumnos, se seleccionaron dos grupos y entonces se analizaron 16 fórums, utilizando principios del análisis de la conversación. El número de mensaje publicados, de intervenciones del tutor y de cadenas enunciativas se asociaron a la calidad. Los resultados muestran que la autonomía en la actuación del tutor, tal como proponer cambios de tópico, incide en la participación y en la construcción de cadenas enunciativas que contribuyen para la percepción de la calidad de la interacción e interactividad.

Palabras clave: Educación a distancia. Relaciones interpersonales. Preceptoría. Medicina de familia y comunidad. 